\title{
Communicating Authority Online: Perceptions and Interpretations of Internet Credibility among College Students
}

\author{
D. Lackaff ${ }^{*}, 1$ and P.H. Cheong ${ }^{2}$ \\ ${ }^{I}$ Department of Communication, University at Buffalo; ${ }^{2}$ Hugh Downs School of Human Communication, Arizona State \\ University, USA
}

\begin{abstract}
This paper discusses how students understand and interpret credibility in their search for online information, especially in relation to websites such as Wikipedia, which present new approaches to authority and information management. Based on focus group and survey data, we found that source authority is not a major determinant in students' informational evaluations, in contrast to some previous research. Due to the difficulty of reliably determining source characteristics and to compensate for this perceived lack of authority, students corroborate information with additional sources and employ other heuristic strategies. Wikipedia poses an interesting epistemological challenge as it represents a relatively novel form of authority and information creation - open editing by semi-anonymous visitors to the site. We find that student credibility assessments are highly pragmatic, and present an expanded model of assessment that accounts for the contemporary communication on the web, with implications for communication researchers and educators.
\end{abstract}

Keywords: Credibility, authority, education, personal epistemology, wikipedia.

\section{INTRODUCTION}

In recent years, digitization and the deployment of new communication technologies have increased the accessibility of scholarly writing and research findings. Amazon.com and Google, for example, have expended significant effort to digitize books, making these texts clickable, linkable, and searchable. In addition, the relatively low entry costs for individual online content production makes possible information sharing with potentially large audiences in a short period of time. However, the emerging popularity of free, community-authored online resources, including books and encyclopedias, may challenge or subvert traditional informational paradigms and communication behaviors among laypersons and instructional authorities. For example, a website containing information about a particular health concern can technically be created with equal ease by a medical practitioner, a pharmaceutical marketing team, a patient with the condition or a student, and it is possible that the quality of information across the sites would vary considerably. Compounding the challenge of online information evaluation is the fact that authorship (which is generally taken for granted in the print publishing world) may not be as reliable or consistently presented online. Anyone could create a website and falsely claim to be a professional with impeccable qualifications. Further challenges to users' assessment strategies include a relative lack of filtering mechanisms, the interface characteristics of hypertext systems, the relative lack of source attributions, and an ambiguity regarding best evaluation practices (Danielson, 2005).

In light of the evolving online communication platforms, this paper critically explores the notions of authority and

*Address correspondence to this author at the Department of Communication, University at Buffalo, Buffalo, NY, 14260-1020, USA;

E-mail: lackaff@lackaff.net credibility in the context of higher education, where the Web has become the starting point for research among many communication undergraduates, often to the chagrin of instructors and librarians. This paper investigates the general perceptions of credibility online as well as the specific perceptions of credibility with regard to information available on Wikipedia. Wikipedia is an open access, community based encyclopedia, collaboratively written by a cadre of volunteer editors, and managed by a nonprofit foundation (Wikipedia:About, 2007). Wikipedia is among the top 10 most popular sites on the Web, and a survey from the Pew Internet and American Life project indicates that $44 \%$ of American Internet users ages 18-29 look there for information (Rainie \& Tancer, 2007). However, in contrast to other reference sources, such as published textbooks and encyclopedias, Wikipedia's contributors and editors are largely anonymous (or pseudonymous). With a few minor exceptions, every Wikipedia article is open to editing by anyone who accesses the webpage, and any user can create a new article page. The information provided is expected to project its own authority, and the process of iterative drafting is expected to result in higher levels of quality. Given this newer model of knowledge presentation and organization based on shared consensus, how do students perceive and evaluate the credibility of this information? The answers to this question are highly relevant to communication scholars and educators alike, as they attempt to promote positive student outcomes in terms of Internet literacy (Metzger, Flanagin, \& Zwarun, 2003), and to better understand changing systems of information production and dissemination.

We seek to understand and examine credibility assessments, since the capacity to assess online information is increasingly being recognized as a critical communication asset in this contemporary "age of information." Indeed, as Hofstetter (2005) notes, understanding the Internet and 
knowing how to use it effectively is no longer just a skill but is a necessary "literacy." The focus here is on college students as several commentators have noted how these allegedly tech-savvy, "digital natives" of the "Myspace generation" ironically lack Internet related competency, such as search skills (Hargittai, 2002), web fluency (Bunz, 2004), and computer and Internet use and problem solving behaviors (Cheong, 2008). Based on quantitative and qualitative findings from surveys and focus groups, we propose to examine an expanded model of credibility assessment that takes into account the increasingly collaborative nature of online knowledge production.

\section{Understanding Online Credibility and Changing Authority Structures}

Online information evaluation draws from multiple bodies of literature ranging from information science, psychology, marketing, and health science. In recent years, few studies in communication research have examined the changing notions of perceived credibility and online information evaluation, although there exists some prior research on media richness theory that attempt to link task and communication media characteristics to task performance and satisfaction in organizational settings (Daft, Lengel, \& Trevino, 1987; Trevino, Lengel, \& Daft, 1987; Suh, 1999). A key organizing principle of credibility research has traditionally been its "object" of assessment, such as source credibility, media credibility, and message credibility (Rieh \& Danielson, 2007). However, new communication technologies have complicated this delineation, especially since the distinction between customary components of communication, including source, medium, and receiver becomes blurred (Flanagin \& Metzger, 2007). In the absence of reliable cues to authorship, "the Web" may be increasingly viewed as a message source, rather than a medium, by laypeople and scholars alike. Consequently, a pertinent new media and communication issue on online credibility is the nature of the evaluative process of information online.

To date, more prominent coverage has been placed on theories of information evaluation, which view authority and expertise as a quality of individuals, or a quality that individuals lend to a larger organization. For example, the theory of cognitive authority as applied to online credibility evaluation has been explored extensively by Rieh (2002; 2005) who draws from Wilson's (1983) theory of cognitive authority to explain evaluative processes. Wilson argues that an individual's trust in information is based on the cognitive authority of its source, and that cognitive authority is attributed to sources (including people, organizations, and books) based on contextual and domain-based factors. Rieh (2002) then finds that the credibility of information to potential users flows from the authority of its source. Thus, cognitive authority theory assumes that the individual or institutional source of a message is of primary importance to an individual's assessment process. However, the potentially limited ability of Internet users to determine the source of information poses a key challenge to the establishment of the credibility of online information.

Moreover, the predictions of the cognitive authority theory may not square with the realities of everyday information seeking behaviors, necessitating an examination into other contextual factors that may shape credibility assessments. For example, Eysenbach and Köhler (2002) found that although the authority of the information source was voiced by participants as one of the most important characteristics used in determining credibility, experimental observation revealed that "none of the participants actively searched for information on who stood behind the sites or how the information had been compiled; often they did not even visit the home page" (p. 574). Therefore, in contrast with relying on cognitive authority or "authority from above," another form of authority may emanate not from concrete institutional or individual sources, but from some awareness of the processes of online information creation and organization. This type of "authority from below" may come from trust in Google's search algorithms (which are based on the human-created link structure of the Web; Pan et al., 2007), Wikipedia's distributed editing process (where editors are largely anonymous), or Amazon.com's product recommendations (which are based on previous customers' buying preferences). In other words, authority is not directly assigned to Google, Wikipedia, or Amazon.com, but to the processes they employ to generate useful information.

Related to this alternative source of authority is the use of contextual cues to make determinations of credibility, including the design, organization, tone, and namerecognition of websites (Stanford, Tauber, Fogg, \& Marable, 2002). Specifically, Fogg's (2003) ProminenceInterpretation Theory posits that two things happen when an individual assesses the credibility of online information: first, the user notices a cue (prominence), and second the user makes a judgment about it (interpretation). Both of these factors are highly contextual with regards to the individual and the specific research task. If either the prominence event or the interpretation event does not occur, then there is no credibility assessment. The process of noticing a prominent element and making an interpretation happens repeatedly as a person evaluates a Web site, with new aspects of the site being noticed and interpreted as the user makes an overall assessment of its credibility. It is expected that individuals will repeat these evaluative processes across different Web sites until they are satisfied with their assessment or reach personal or contextual limits.

It follows that in addition to contextual cues perceived and present in the text, a pragmatic component is also present in every evaluative understanding of credibility. If the identity and authority of the author requires significant effort to determine, information seekers will adjust and compensate. In an environment where source authority is difficult or impossible to determine, individuals may seek out other cues to make credibility judgments. For instance, information evaluation may be contingent upon the normative valuation of the contextual cues, especially in light of the amount of information available and present online. In the case of the Internet, the determination of source authority can be very costly in terms of time and effort, especially in relation to the costs of locating new information. Fallis (2004) proposes that all informational quality judgments can be understood as a special case of the "epistemology of testimony," an area of philosophical inquiry that can be traced back to Enlightenment thinker David Hume. Hume's epistemology of testimony was 
originally conceived in light of the need for critical thinking with regards to evaluating interpersonal reports of miracles. If one received a report of a miracle, how should one decide whether or not to believe it? In line with need to judge both the occurrence of the miracle as well the person expressing the testimony, information evaluation becomes a personal, normative, and value-laden project. Library and information science professionals have continued in this tradition, attempting to develop guidelines and strategies that will allow individuals to make accurate credibility judgments about information they find online (e.g. Alexander \& Tate, 1999; Cooke, 1999; Wilkinson, Bennett, \& Oliver, 1997).

In sum, various theories on credibility reviewed suggest multiple perspectives for understanding how individuals adjust to the uncertainty of the online communication environment. Different sources of authority may be used in individuals' credibility perceptions, including cognitive "authority from above" or "authority from below" which captures offline and online contextual sources of authority that are perhaps more prevalent, in individuals' credibility judgments. Findings from prior research, however, are mainly derived from examining general adult information seeking behaviors or credibility assessments in the context of health information (e.g. Eysenbach \& Köhler, 2002), and results may not be generalizable to college students, who work and interact in academic environments with specific knowledge professionals, including librarians and professors. Thus, the next section discusses credibility assessments in the academic context in order to situate and better understand student authority perceptions.

\section{Credibility Assessments in the Academic Context}

Various online resources are becoming alternative or complementary knowledge sources for many college students. According to some researchers, the Internet has become an "informational cornerstone" for American tertiary-level students (e.g. Jones, 2002, p. 19). Findings from a Pew Internet and American Life survey indicate that large majorities of students report to have a positive attitude towards the Internet (89\%), find that the Internet has had a positive impact on their college academic experience $(79 \%)$ and use the Internet, rather than the library, as the primary site of information searches (73\%) (Jones, 2002). However, many academic librarians have expressed concern at this increasing reliance on the Internet, that today's students are "lazy, procrastinating, plagiarizing patrons of the glut of information that has come to be known as the Internet" (Thompson, 2003, p. 259). A significant challenge for colleges is thus to provide students with the skills and strategies necessary to locate and evaluate information on the Internet. As a formal educational practice, the development of this skill has been most tackled by library scientists who have attempted to distill best practices into formal guidelines and textbooks (e.g. Alexander \& Tate, 1999; Cooke, 1999; Smith, 1997; Wilkinson, Bennett, \& Oliver, 1997). Some tertiary institutions require a library skills course as part of the core curriculum for all students, but such opportunities may be rare. The authors' institution, for example, requires that undergraduates complete an online library usage tutorial, but the tutorial focuses on finding rather than evaluating information, thus pointing to potential knowledge gaps in credibility assessments.
Tertiary students have several characteristics that may set them apart from the general Internet-using population. A broad body of literature has examined Internet health information seeking behavior (e.g. Eastin, 2001; Jadad \& Gagliardi, 1998; Eysenbach \& Köhler, 2002), and it has been noted that the outcome of such behavior can be a matter of life or death (Eysenbach, Powell, Kuss, \& Sa, 2002). Such information seekers may be inclined to employ robust strategies of information evaluation. Students, on the other hand, primarily seek information to complete academic projects and papers or for entertainment (Jones, 2002), and may approach Internet information with a more cavalier attitude (Thompson, 2003). Students' use of the Internet is in some ways distinctive, for example, as they are much more likely to download and share files, and communicate using instant messaging and chat software (Jones, 2002). As information-seekers, students have unique properties. Metzger, Flanagin, and Zwarun (2003) found that students were more likely than the general population to view the Internet as a credible source for news, reference, and entertainment information. In a substantial meta-analysis of research on electronic reference use, Tenopir (2003) finds that convenience is the most important factor in students' information use, pointing to the importance of pragmatism in students' understanding and use of online materials.

Students' beliefs about information may play an important role in their evaluative behaviors. A burgeoning body of literature is attempting to determine the role of epistemological beliefs in the learning process (see Hofer \& Pintrich, 2002, and Educational Psychology, 27(2) for surveys of this field). Whitmire (2004) measured 15 students' levels of epistemological development (higher developmental levels correlate with more sophisticated understandings of information). She found that students at higher levels of development looked to a wider range of cues (such as source attributes and authorship). The task of an information provider is then to convincingly project this authority through media such as websites. Sources such as Wikipedia are disruptive to this traditional understanding of credibility as they place little or no emphasis on veritable credentials of their authors and editors.

We identify two personal epistemological characteristics that may affect individuals' online credibility assessment. Wood and Kardash (2002) note that student's beliefs about the speed at which knowledge can be obtained and about how knowledge is constructed and modified are important components of the overall epistemological belief system. These two factors are especially relevant to understanding online credibility judgments. Students who believe that true knowledge is always obtained rapidly may exhibit online search and appraisal behaviors that differ from those who believe knowledge can be obtained slowly with effort. Likewise, students who believe that knowledge is a static reflection of the real world may understand online information sources differently from those who believe knowledge is tentative and subject to negotiation. We expect that more sophisticated epistemological beliefs along these two factors should be associated with less trust in traditional authority, and its associated cues, a higher need to verify found information, and increased trust in collaborative knowledge-generation processes such as Wikipedia's. 
Moreover, research suggests that traditionally authoritative reference sources - peer-reviewed journals, books from university presses - are declining in student use relative to Internet reference sources. Longitudinal research of citations in student term papers by Davis (2003) showed a steep decline in traditional reference source use throughout the last half of the 1990s, accompanied by a rise in Internet citations. This increase in Internet use for student research coincided with other phenomena such as a mean 55\% drop in reference requests for academic librarians between 1995 and 2005 (Association of Research Libraries, 2006), and the networking of college dorm rooms (Davis, 2003). The primary cognitive authorities in most students' academic lives - their professors - have a generally positive view of the Internet as a reference source, and tend to allow its use for student papers and projects (Herring, 2001). However, different professors often do not communicate a consistent set of informational values to students, and have general, rather than specific concerns about aspects of Internet referencing behavior (Herring, 2001). If librarians and instructors are now less central, and less authoritative, in informational tasks than previously, what communicative behaviors and schemas are filling this void?

These factors, in addition to the increasing convenience of finding and using online information, place students in an uncertain communication environment online. When students choose to perform academic research tasks in their dorm room, rather than at the library, they navigate this environment learning by trial and error. Wikipedia presents an especially interesting case for discussions of credibility, as it has become a central component of the student's communication landscape while simultaneously accentuating issues of authorship and authority that have long been viewed as problems.

To help gauge the social environment in which students are searching for information, we employ two measures. First, Vishwanath's (2007) Information search efficacy scale shows how comfortable individuals are with performing information search tasks, and how confident they are in their ability to achieve positive informational outcomes. Cheong's (2008) social support of Internet use measures the social support individuals feel they have access to with regards to technology use. Together, these measures represent the context in which they are searching for information, ranging from low-efficacy individuals with limited social support to high-efficacy individuals with ample social support. We expect that high efficacy and social support will be associated with more use of non-traditional knowledge sources such as Wikipedia, as such characteristics should lead to less reliance on traditional conceptions of credibility and authority.

Given our discussion of the above factors - distinct informational needs and behavior of the student population, individual variations in personal epistemological sophistication, and distinctions of the Web medium - we propose that an expanded model of credibility assessment is needed to comprehensively understand students' perceptions and interpretations of credibility online. In the new media environment where source authority is difficult or impossible to determine, we expect that individuals will seek out other cues to make evaluative judgments. In the case of online information, making judgments about source authority ("authority from above") can be very costly, in terms of time and effort, especially in relation to the costs of locating new information. We believe that some students will employ a pragmatic approach to credibility, and rely heavily upon alternative sources of authority, such as corroboration, technical and social processes, and accessibility ("authority from below") to fulfill their needs for credible information. (Fig. 1) illustrates this expanded model, and shows how different factors in the new Internet environment are related to students' new approach and perspective on authority, credibility, and Internet information.

In sum, this study explores students' evaluative processes with regards to online information and Wikipedia more specifically. This paper examines credibility at both the Web site and message levels (Rieh \& Danielson, 2007), and is organized around three research areas, (a) the extent to which students attributing credibility to online documents, (b) the processes whereby students are interpreting and evaluating the information they find online, and (c) the ways in which students are evaluating informational sources such as Wikipedia, where verifiable authorship has been distanced from the information provided.

\section{METHOD}

A multipronged approach was used to assess the validity of the pragmatic credibility model, which included a series of focus groups and an online survey. The focus group phase of this study informed the subsequent development of the survey instrument, in a design recommended by Krueger (1994) for exploratory analysis of new research questions. Focus groups allowed us to both test potential survey items and improve our understanding of the processes in question. Further, the focus groups provided a rich body of data that helped us better interpret the findings from the survey. Data collection and analysis was approved by the Social and Behavioral Sciences Institutional Review Board at the State University of New York at Buffalo. All participants for this study were recruited from an introductory communication course, where they received course credit for their participation. The data collection process proceeded between March 2007 and March 2008.

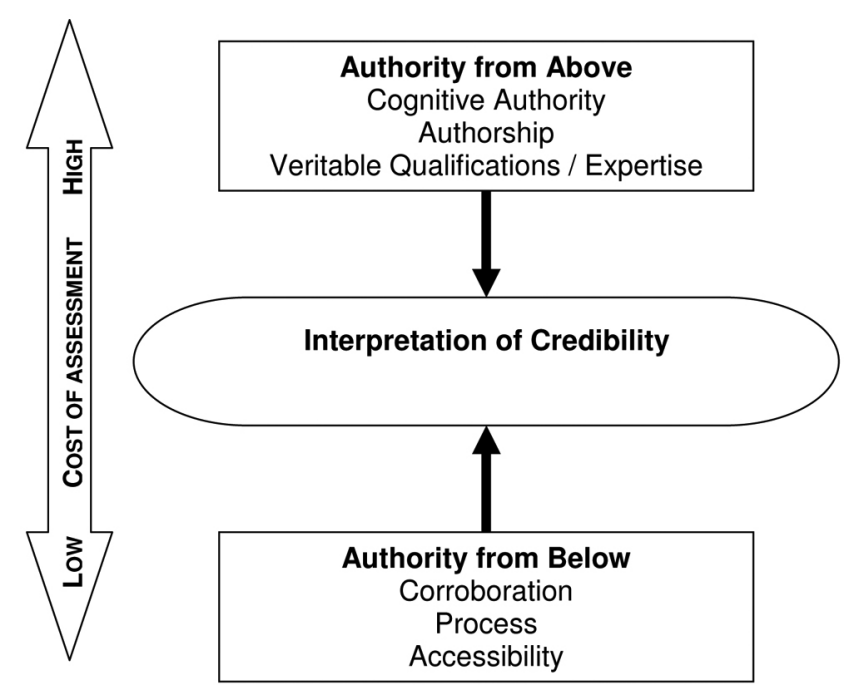

Fig. (1). Expanded pragmatic model of credibility assessment. 


\section{Focus Groups}

42 participants participated in five focus group sessions, each of which consisted of 7-10 participants and lasted for approximately one hour. Upon arrival at the meeting location, individuals were briefed on their participant rights, signed a consent document that provided for audio recording, and were then asked to fill out a brief survey about their previous Internet experience and use of the Internet as a reference source. Each focus group began with a general discussion of online information and students' evaluative processes, and later was guided to more specific issues of Wikipedia and collaboratively-generated reference information.

\section{Online Survey}

The survey was implemented using LimeSurvey, an open-source web survey application. After clicking a link provided by their course instructor, participants were directed to an information sheet detailing their rights as a participant. After acknowledging their understanding of the survey procedure, they were presented with a series of webpages containing the survey questions. Upon completing the instrument, participants were directed to print a confirmation page to submit to their instructor for credit (as data were collected anonymously). 272 participants completed the survey.

The survey contained multiple variable measures to test the expanded model of credibility interpretation, including factors relating to personal epistemology, Internet search skills, and social contexts of technology use, as well as "cues"-based approaches to credibility interpretation. Epistemological beliefs were measured by two factors in Wood and Kardash's (2002) Epistemological Belief Scale: Speed of knowledge acquisition ${ }^{1}(\mathrm{a}=0.793)$ and Knowledge construction and modification ${ }^{2}(\mathrm{a}=0.716)$. Vishwanath's (2007) Information search efficacy ${ }^{3}$ scale is a five-item measure of an individual's confidence in their ability to locate information. The reliability of this scale was .877 .

\footnotetext{
${ }^{1}$ Speed of knowledge acquisition was measured by the following items on a 5-point scale of agreement: (a) If something can be learned, it will be learned immediately. (b) Almost all the information you can understand from a textbook you will get during the first reading. (c) You will just get confused if you try to integrate new ideas in a textbook with knowledge you already have about a topic. (d) Working on a difficult problem for an extended period of time only pays off for really smart students. (e) Usually, if you are ever going to understand something, it will make sense to you the first time. (f) If I can't understand something quickly, it usually means I will never understand it. (g) Most words have one clear meaning. (h) The information we learn in school is certain and unchanging.

${ }^{2}$ Knowledge construction and modification was measured by the following items on a 5-point scale of agreement: (a) The only thing that is certain is uncertainty itself. (b) Forming your own ideas is more important than learning what the textbooks say. (c) A really good way to understand a textbook is to reorganize the information according to your own personal scheme. (d) You should evaluate the accuracy of information in textbooks if you are familiar with the topic. (e) Wisdom is not knowing the answers, but knowing how to find the answers. (f) Today's facts may be tomorrow's fiction. (g) The most important part of scientific work is original thinking. (h) Even advice from experts should be questioned. (i) I try my best to combine information across chapters or even across classes. (j) A sentence has little meaning unless you know the situation in which it was spoken. (k) I find it refreshing to think about issues that experts can't agree on.

${ }^{3}$ Information search efficacy was measured by the following items on a 5-point scale of agreement: (a) You can search for information on a topic even if you knew nothing more about the topic. (b) You can search for information on a topic without help from anyone. (c) You can search for information on a topic even if no one showed you how to search for the information. (d) You can search for information on a topic if you had no access to computing technology such as the Internet or personal computers. (e) You can search for information on a topic even if the information is not available online.
}

Cheong's (2008) Internet social support ${ }^{4}$ scale is a five-item cumulative measure of an individual's access to social support for computer and Internet problems. A range of Search task items assessed the frequency of searches for certain types of information (e.g. academic, entertainment, current events) with a Likert-type scale of search frequencies $(1=$ "once per year or less" to $6=$ "daily").

The Credibility cues were a series of cues identified in the literature and by focus group participants as having some correlation with online information credibility. Participants were asked, "How will each of the following affect your decision to use the information?", prompted with a range of cues such as "page contains commercial advertising" and "page lists an author," and responded using a five-point Likert-type likelihood scale. Participants also responded to items testing Information search and assessment behavior. These items asked how many pages of search results they would scan, what type of effort (if any) they would expend to verify Internet sources, and their use of different types of information websites, including Wikipedia.

Finally, the demographic data collected included Age, Sex (dummy coded as 1 = female, 2 = male), Cultural background, Class year, and Academic major.

\section{ANALYSIS}

Given the exploratory nature of this paper, data from both the quantitative survey and qualitative interviews were triangulated to allow comparison of information sources and the verification of the validity of information received. The focus group discussions were digitally audio recorded, transcribed, and then processed to remove personallyidentifying information. The discussions were then manually coded using Weft Qualitative Data Analysis software, an open-source tool that allows for fast and efficient coding of qualitative data. A coding schedule was developed based on preliminary analyses of the data, and was then applied to the entire data set. The online survey results were exported from the website directly to SPSS for analysis. Descriptives were tabulated by frequencies and standard deviations. Pearson correlations were tabulated among the 6 factors (Speed of knowledge acquisition, Knowledge construction and modification, Information search efficacy, Internet social support, Search task, Credibility cues, and Information search and assessment items) and demographic variables, All statistical analyses were performed using SPSS 15.0 and employed a .05 level of significance.

\section{RESULTS}

\section{Demographics and General Information Search Behavior}

Of the focus group participants, 27 were female, 15 were male, and the average age was 20 years old $(S D=1.0) .27$ were first- or second-year students. Of the 272 survey participants, 141 were male, 122 were females ( 7 noresponse) The mean age was 20 years old $(S D=2.4) .174$ $(63.9 \%)$ participants were first- or second-year students The

\footnotetext{
${ }^{4}$ Internet social support was measured by the following items on a 5-point scale of agreement: (a) I am very confident with solving computer problems by myself. (b) I have a special someone on whom I rely on when I need to solve computing problems. (c) I can count on my friends when things go wrong with my computer. (d) I have a special person who is a real source of help to me when I encounter problems with my Internet. (e) I have friends with whom I can share my Internet related problems.
} 
primary cultural affiliations were mainstream American (61.0\%), East Asian (10.3\%), European (10.3\%) and African-American (3.7\%). In addition to demographics, the structure of students' informational search behavior can help characterize the sampled population. The online survey assessed the frequency of different types of information searches. Correlations among demographic and independent variables and frequency of topical searches (entertainment, current events, shopping, travel, history, health, career) in the online survey are provided in Table 1. While all search topics are significantly correlated with one another, a few other correlations of topics with the independent variables are notable. Social support is significantly correlated with frequency of searches across all topics, suggesting that individuals with ready access to social problem-solving resources are making more use of Internet information, including for academic purposes $(r=0.126 . p<.05)$. Selfefficacy is significantly correlated with frequency of searches for academic information, indicating that confidence in one's ability to locate needed information results in more Internet use for academic tasks $(r=0.234$. $p<.01)$.

\section{Student Perceptions of Online "Source" and "Authority"}

Participants overwhelmingly indicated that the Internet is one of the first places they turn to fulfill informational needs, consistent with previous findings of the centrality of new communication technologies in the student's informational environment (e.g. Jones, 2002). "The Internet" was a highly encompassing term that referred to online journal databases accessible though the library as well as the resources available on the wider network. According to the majority of the participants interviewed, the Internet was clearly central to the research process, often to the exclusion of other media:
"I can honestly say I've never set foot in this [campus] library, and I've never set foot in my community college library. I've only been in my high school library because we had to be. I don't rely on books. I actually haven't bought any textbooks for this year at all..."

"I rely mostly on the Internet, but I do know how to search, and I do know how to find credible information. If there is a situation that does call for a book, I will find it through the Internet. I don't know, I've just... never had a problem up to this point."

"I still use the Internet a lot, because I find that in the stuff I usually research or am interested in changes a lot from year to year, so it's really hard to go pick up a book and cite that versus what's new and what's happening now."

Only four participants expressed some preference for more traditional information sources, such as:

"If I'm doing research on current events I'll usually go online... but other than that I try to stick to the books 'cause they're a lot more credible than online material in my opinion."

Search engines, particularly Google, are the primary gateway to this content, with many students actually referring to websites as "Google websites" and "Google sources." When compared to offline reference sources, "the Internet" was viewed as excelling in convenience and accessibility, but also as a less reliable source of quality information. While recognizing the breadth of information that is available, many participants claimed to maintain a broad skepticism about the accuracy of information they found. Participants stated:

"I think you have to do research on your research, and the Internet has offered us a lot more information and that's a blessing, but at the same time you have to be careful.

Table 1. Significant Zero-Order Correlations for Topic Search Frequencies $(* p<.05, * * p<.01)$

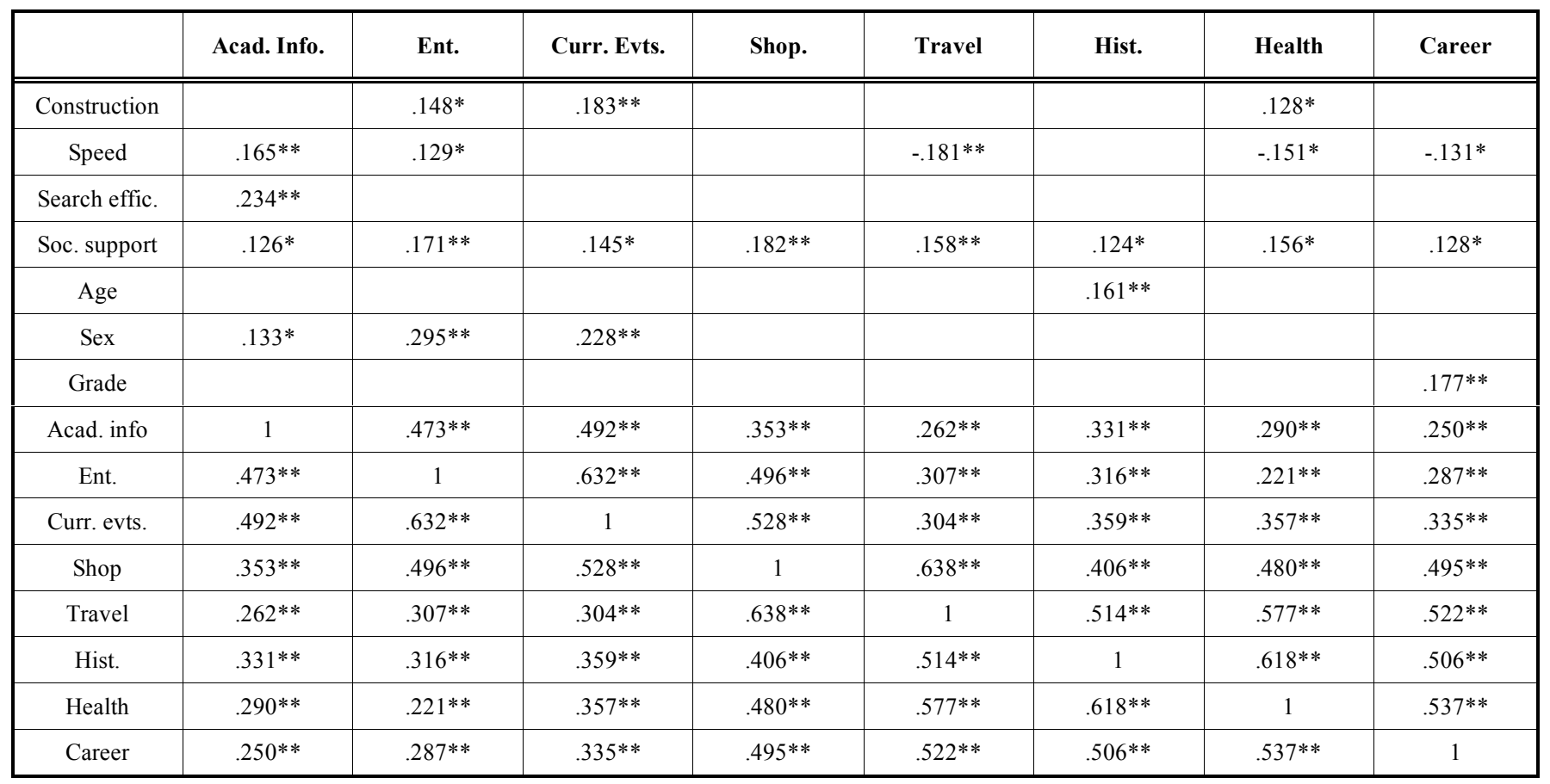




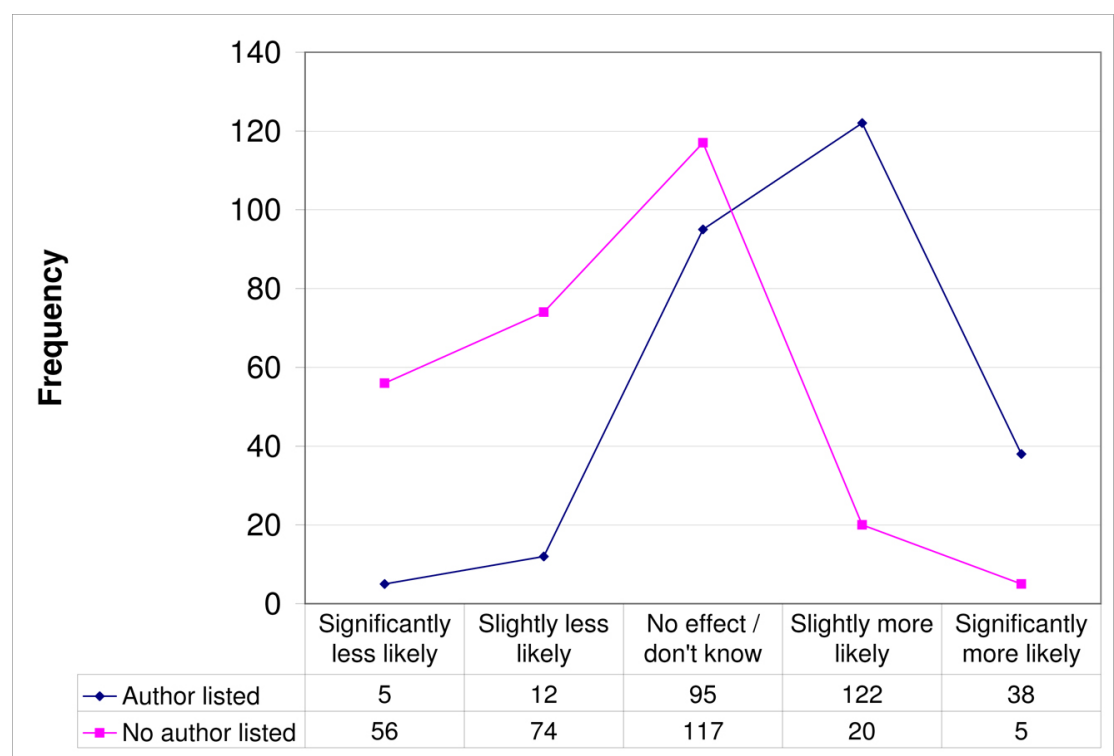

Fig. (2). Webpage authorship and willingness to use information.

"Half of the results on Google are usually advertisements of some sort, trying to get you to do something... The regular page on the web is not credible at all."

Authorship was consistently rated as one of the most important indicators of credibility in the focus groups, and this was supported by results from the online survey. The mere presence of an author's name on a web document appears to strongly increase the credibility of a given web document, as indicated by the survey results in Fig. (2). However, the authority of the author was only raised as an issue by a single focus group participant, in the context of an affiliation with a university. The rest of the participants were content to simply find a named author - "real people who have written the text." None of the students indicated that verification of authorship was a priority when they were performing research:

"There's so much stuff out there, you can't have a credible source without an author... If I did research I would just try to do the bare minimum and just put any resource down, it was like 'Oh, no author, okay, I'll just skip [to] the next step in citing the source."”

When prompted with the cue "page lists an author with expert credentials," 197 online survey respondents $(72.4 \%)$ indicated that they would be slightly or significantly more likely to use the page's information. The importance of authorship qualities are shown in the correlations in Table 2. Self-efficacy is significantly related to attitudes toward all four authorship cues. Speed of knowledge acquisition, knowledge construction and modification, and age were positively related with a preference for a listed author. These three factors, plus social support, were also positively related to a preference for expert credentials. As shown in Table 2, a web page's pseudonymous authorship or lack of listed author was negatively correlated with several factors, including speed of knowledge acquisition, knowledge construction and modification, and search efficacy. Further, just under half (133) of the online survey sample stated that they had previously attempted to verify the authorship of a web document.

Table 2. Significant Zero-Order Correlations for Authorship Cues $\left({ }^{*} p<.05,{ }^{* *} p<.01\right)$

\begin{tabular}{|c|c|c|c|c|}
\hline & Page Lists Author & $\begin{array}{l}\text { Page Lists Author with } \\
\text { Expert Credentials }\end{array}$ & $\begin{array}{l}\text { Page Lists Pseudonym or } \\
\text { "Username as Author }\end{array}$ & Page Lists no Author \\
\hline Const. & $.203 * *$ & $.276^{* *}$ & & $-.143^{*}$ \\
\hline Speed & & $.247 * *$ & $-.247 * *$ & $-.207 * *$ \\
\hline Search effic. & $.122 *$ & $.228 * *$ & $-.169 * *$ & $-.132 *$ \\
\hline Soc. support & & $.160^{* *}$ & & \\
\hline Lists author & 1 & $.703 * *$ & & $-.302 * *$ \\
\hline Expert cred & $.703 * *$ & 1 & & $-.254 * *$ \\
\hline Pseudonym & & & 1 & $.456 * *$ \\
\hline No author & $-.302 * *$ & $-.254 * *$ & $.456 * *$ & 1 \\
\hline
\end{tabular}




\section{Influence of Contextual Cues on Perceptions of Credibility}

Previous research in the area of evaluative processes has examined the role of "quality indicators" - visible or structural aspects of an information source that can be used as cues to its quality (e.g., Griffiths \& Christensen, 2000; Fallis \& Frické, 2002; Kunst, Groot, Latthe, Latthe, \& Khan, 2002; Frické \& Fallis, 2004). Examples of such indicators include the top-level domain (TLD) of a website (.com, .edu, .gov), the presence of advertising, the listed credentials of the author, and the date of the last page update.

Participants in each focus group were asked to identify and describe such cues, and were then asked to comment on some specific indicators. Before being prompted by the moderator, few participants volunteered any such indicators. A notable exception was the top level domain of websites, with most participants stating that the TLD was important to their evaluation:

"I took a computer class and they taught us to make sure it's... credible. Like, dot org, dot edu. Basically they spent like half the class showing us which ones would be credible and which ones wouldn't be, and how to tell."

"If I'm searching for something school-related, a lot of times the websites that come up, even just Googling them, are from like actual universities... like if it's dot edu or something like that, I'll take that as being more reliable than just some random website 'cause it's like published by some university that you've heard of, it's probably reliable, I would hope."

However, interpretations of TLDs were inconsistent, with most participants indicating that ".com" was a potential cause for skepticism, in contrast to ".edu" or ".gov". The survey results were consistent with this discussion, indicating that students find edu and gov much more credible than other TLDs. Survey participants were presented with the five most common TLDs, and asked to evaluate the impact the TLD would have on their decision to use information found on such a site using a 5 point Likerttype likelihood response scale. These results are shown in Fig. (3), and indicate that .edu and .gov TLDs are seen as more credible, while the other listed TLDs are viewed as less credible. When all the TLD results in the survey were compiled into a single variable (a measure of how much attention, overall, the individual affords the webpage's TLD), the Knowledge construction and modification variable was significantly correlated $(r=.233, p<.001)$.

Focus group participants had some awareness of domain name assignment, recognizing that .com domains are more easily acquired than .edu domains, for example. Yet even this simple rubric was not universal: several participants believed that the .org or net TLD could only be used by nonprofit organizations, and that such websites would contain higher quality information that .com websites (although there are no important technical distinctions between .com, .org. and .net).

Focus group participants were prompted with indicators which are commonly identified as "credibility cues", such as authors and their credentials, age of the information, page layout (graphics, colors, design), ownership of the page or domain, and placement within search results. Of these indicators, participants were consistently aware of the availability of authorship information (as previously discussed) and the layout and organization of the web page in question:

"If it just looks like it was pieced together in about five minutes, I typically just go right past it, but if... they actually went through enough trouble to make the whole page look elaborate, and everything is well sorted and easy to find, then I see it as more reliable right away."

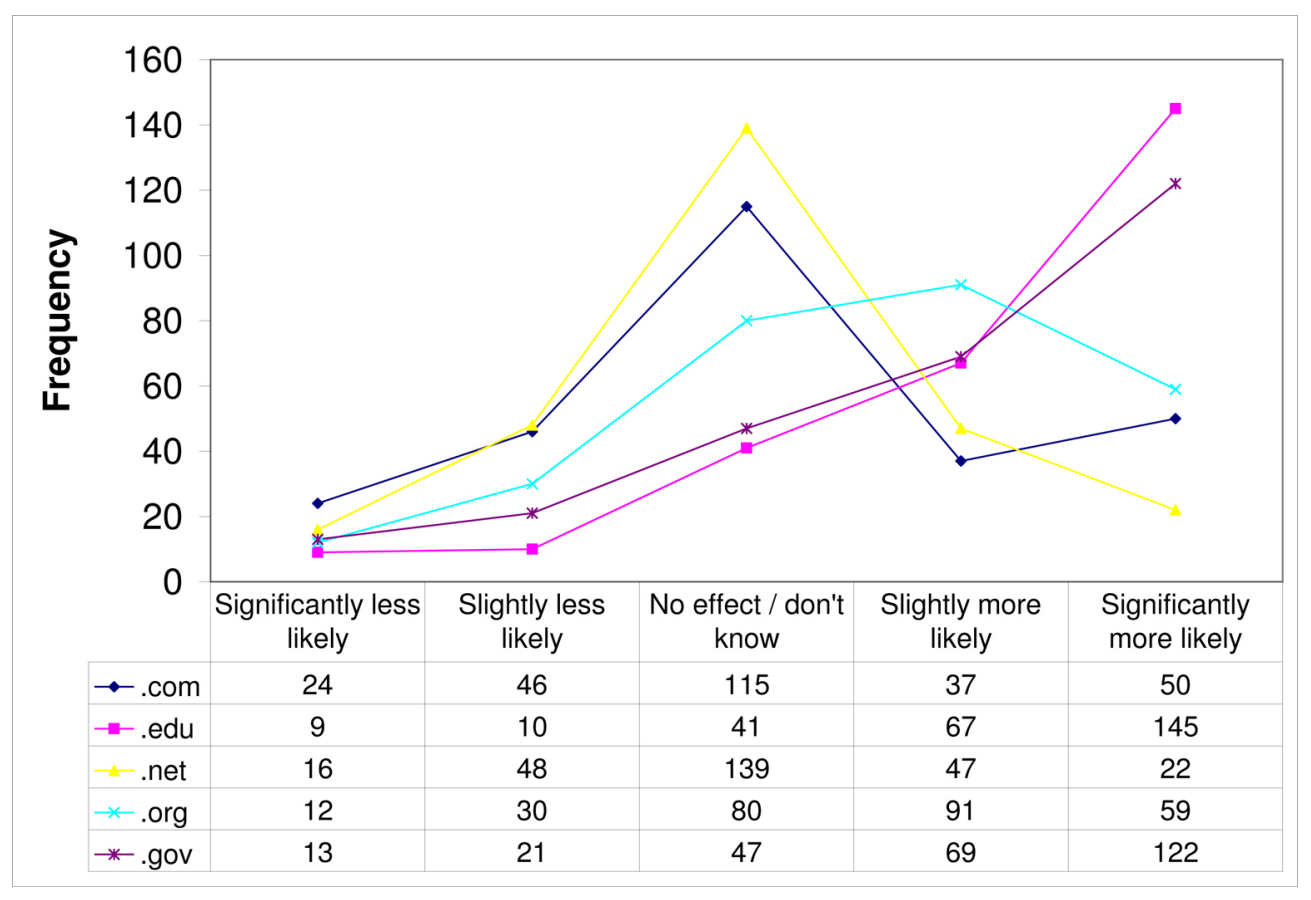

Fig (3). Website TLD and willingness to use information. 


\section{Perceptions of Online Credibility Efficacy}

Students tend to regard themselves as relatively savvy with regards to computer and Internet use, with participants reporting that they are generally confident in their information seeking abilities $(M=3.6, S D=0.851$ on the information search efficacy scale). In the focus-groups, selfassessments of evaluation efficacy were also generally positive. Most participants were confident that they could distinguish between high-quality and low-quality information. Interestingly, most reported that this efficacy was self-taught and had developed over time. Only a few participants were less confident in their abilities:

"My biggest fear is submitting work that is not credible... There aren't as many classes offered on how to be savvy with the Internet in terms of research."

"The Internet seems like dangerous territory."

"I think it's hard to decide if something is credible on the Web. Something might look like it, might have references and have the author, but because you're researching, you're researching because you don't know something."

Several focus group participants identified this last concept as a fundamental challenge of their research endeavors: if one is unfamiliar with her topic, she may have a limited heuristic toolset to use in the evaluation of found information.

Finally, focus group participants were asked about formal instruction they had received from high school or college instructors with regards to using Internet reference sources. Approximately half had received no general instruction on Internet references, and the remainder had been instructed to only use references available through the library, such as library-created "department resource pages" and journal databases. While some participants report following this advice, a more common reaction was "I still use Google, even though I was told not to. It's just so much easier."

\section{Wikipedia Use and Evaluation}

The second phase of the focus group discussions focused on participants' understandings and uses of Wikipedia. Most of the online survey participants reported at least some familiarity with the site. Familiarity was significantly correlated with Knowledge construction and modification $(r$ $=.292, p<.001)$, Speed of knowledge acquisition $(r=.155$, $p<.015)$, information search efficacy $(r=.191)$, and Sex (male) $(r=.165, p<.006)$. However, while 151 online survey participants $(55.5 \%)$ indicated that they were "very familiar with this site" and had "a good understanding of how it works," only $10(3.7 \%)$ reported that they knew how to edit a Wikipedia article, and $2(0.7 \%)$ had actually done so. In other words, results show that students' self-reported knowledge of Wikipedia as collaboratively constructed does not necessarily correspond with a comprehensive awareness of how the collaborative editing process functions.

Among focus group participants, skepticism about open editing was much more common than the acknowledgement of its benefits, with eight participants voicing this concern. As one participant opined, "anyone can go on [Wikipedia] and make up any kind of crap they want." With the exception of a participant who had actually inserted inaccurate material into an article and seen it promptly removed, none of the participants indicated an awareness of any quality-control processes that occur on Wikipedia, such as the technical simplicity of vandalism control (just a few clicks of a mouse) and the preponderance of editors dedicated to improving articles in their domains of interest (Lih, 2004) :

"I could go on there and say anything, and somebody who doesn't know anything about that topic will believe me, and then their paper is screwed."

"Sometimes [Wikipedia] will have information, it could be correct, but still, any random person could write it down on there."

Eight participants reported that their instructors shared this view:

"I had a professor that was furious with [Wikipedia]. He said if we ever used it that he would... rip up our paper and give us an F."

Accordingly, many participants explained that they used Wikipedia only to look up trivia or unimportant topics, where any inaccuracy would have little consequence. They noted that it was especially useful for quick factual information lookups, or what Frické and Fallis (2004) term "ready reference" questions:

"I think it's good for quick referencing... I found a band's discography on there... when each album was released, and the songs on each album."

"I use Wikipedia for just general information. If I... wanted to learn about something, anything, ... most of the time Wikipedia has it, even if it's not something that's really really important."

"[I view Wikipedia as] a reference tool ... you go on there and look up ridiculous things that you just kind of want to know, I don't know, after a couple beers or something."

Concerns about the credibility of this information were limited, as the consequences of finding inaccurate information are minimal when the information need is trivial or not "really really important". As one participant stated, to general agreement:

"There's a lot of information on Wikipedia. I don't know how much is legit, but it's there, it's easy, so I use it."

Two participants noted more specific reasons for their positive impressions - one related the story of how he and a friend edited an article as a joke, and was surprised when their "vandalism" was removed within minutes: "there [are] moderators on all the time... they must be taking it seriously." Another participant applauded the idea of broad collaboration among editors: "Wikipedia... is cool, because it's almost like ... having ... a million people in the room, and you can ask any question." Proponents of Wikipedia often cite error-correction and collaboration as significant strengths of Wikipedia (Lih, 2004), so it is perhaps surprising to find that these qualities may be relatively unknown to the sample population.

When asked about their evaluation of individual Wikipedia articles, participants presented a limited range of 
strategies. Many checked for citations and links to corroborating information:

"The good ones usually have a ton of citations; there'll be like two or three pages of citations at the end."

A few had noticed differences in length among Wikipedia articles: longer articles were seen by some to be of higher quality, while other participants argued that long articles might be filled with redundancy. Some participants even argued that Wikipedia articles tended to be too comprehensive, in comparison to other reference sources available on the Internet:

"The stuff that comes up is so in depth, and you really have to read, and I really don't want to. So I take the easy way out and go to a website that's laid out for me, where it's just what I'm looking for, nothing else."

Across all five focus groups, the search engine Google was unanimously declared the entry point to the web for all informational search tasks. Students reported that they commonly accessed Wikipedia due to articles' high placement in Google search results:

"The only thing I've ever really used [Wikipedia] for is when I ... search in Google, and it comes up."

" [I visit Wikipedia because] Google usually pulls it up. It's usually one of the top couple of pages ... so I'll probably end up on there."

A related issue is the broadly apparent misunderstanding of search engine placement. For example, many participants erroneously believed that companies could pay to have their websites rank higher in Google search results. Further, participants had multiple perspectives on this (nonexistent) practice, ranging from "it's not a good thing, you search for something and the web who pays more will get listed first" to "if a company is actually paying to advertise that information there, in the first few pages, then it might be important for you to know." Wikipedia articles are often highly ranked in Google search results, so mistaken perceptions of what high placement means may have important repercussions.

\section{DISCUSSION}

The picture that emerges from this exploration of students' online research behavior points towards complex answers to this paper's research goals. Our first two research areas addressed the general processes of online information credibility evaluation among students. Although today's college students have grown up using the Internet, and are generally confident in their ability to use it for research purposes, we found that they have given little thought to the evaluative strategies they employ with found information. Few students could elucidate their preference for traditionally authoritative reference sources such as scientific journals over online resources. In one focus group, this topic was raised explicitly, and participants could not present a rationale beyond their instructors' preferences and warnings. One participant argued, "I guess the person who writes the journal [sic] knows what he's supposed to write, so... "This is in line with Whitmire's (2004) findings that many undergraduates have relatively unsophisticated epistemological beliefs, and tend to appeal to personal cognitive authorities, such as instructors, for guidance.

A decade after the first cue-based recommendations for credibility evaluation appeared (e.g. Alexander \& Tate, 1999; Cooke, 1999; Wilkinson, Bennett, \& Oliver, 1997), we find little evidence that students have internalized any such rubric. When prompted with particular cues, students are able to respond with preferences in line with these recommendations, particularly with regard to authorship. However, the inability of the focus group participants to generate these cues spontaneously suggests that they may not be using cue-based heuristics in their day-to-day use of the web. This finding is perhaps welcome, surprisingly, in light of recent research indicating that there is little actual correlation between the presence or absence of such cues and information accuracy (Griffiths \& Christensen, 2000; Fallis \& Frické, 2002; Kunst et al., 2002; Frické \& Fallis, 2004).

For the students in this study, accessibility trumps authority as an indicator of credibility, which is a finding in line with previous research (Tenopir, 2003). The difficulty of verifying authorship of found online information forces individuals to look to other cues about information quality. Previous research has indicated that the characteristics of an informational source, such as institutional affiliation and the author's credentials, are the primary determinants of the information's perceived credibility. When research subjects are asked to self-report factors influencing their credibility judgments, source authority is commonly reported as a critical factor (e.g. Eysenbach \& Köhler, 2002; Whitmire, 2004; Liu \& Huang, 2005). Some experimental research, however, indicates that source authority may actually be only a minor factor in the credibility evaluations of nonspecialist populations. Approximately eighty percent of Eysenbach and Köhler's experimental participants, drawn from a general adult population, were unable to recall the source of found information in post hoc interviews, indicating a weaker link between authority and credibility that is often discussed. Likewise in the present study, the authority of information authors was not found to be a major factor influencing credibility judgments; rather, the perception that information was not anonymously authored was revealed to be more important than the authority of the author.

Social context of information use correlates with search behavior as reflected in the proposed expanded model. Social support is significantly correlated with frequency of searches across all topics, suggesting that individuals with ready access to social problem-solving resources are making more use of Internet information. Internet search selfefficacy is significantly correlated with frequency of searches for academic information, indicating that confidence in one's ability to locate needed information results in more Internet use for academic tasks.

Our third research goal pertained to the evaluation of online information sources with ambiguous authorship, such as Wikipedia. We found that one of the major reasons that Wikipedia has become so important to this population is its accessibility. While web experts may make full use of the capabilities provided by modern search engines - Boolean logic, domain restrictions, and so on - "average" users may not make use of them. "Research," for many students, often 
entails a simple keyword search on Google and examining the first few pages of results (Eysenbach and Köhler, 2002, observed similar behavior in their experiments). Due to several technical factors in the way Google and other search engines rank search results, Wikipedia articles tend to be ranked highly. Several focus group participants commented that they never visit Wikipedia directly, but simply follow links to the site from their Google search results.

A notable finding from the survey was the cognitive disconnect between "familiarity with Wikipedia" and understanding the site's collaborative editing process. The number of individuals who reported that they were knowledgeable about Wikipedia's editing process, or had actually edited Wikipedia articles themselves, was very low, confounding attempts at statistical analysis. Epistemological sophistication, as measured by the speed of knowledge acquisition and knowledge construction and modification factors, were significantly positively correlated with Wikipedia familiarity, suggesting that individuals with more sophisticated beliefs about knowledge may be more likely to make use of the site. Further, individuals with higher levels of search efficacy are also more familiar with the site, perhaps since they are more confident in their ability to evaluate uncertain or questionable information. Interestingly, we found no significant correlations among our measured variables with perceptions that information found on Wikipedia was more or less credible that information found elsewhere on the Web (with the exception of age, in which older participants found Wikipedia to be slightly more credible than younger participants.)

We thus find support for our contention that student credibility assessments of online information are highly pragmatic, and the idea that "authority from below" may be supplanting the role of more traditional forms of authority in student credibility evaluations. Student credibility heuristics are based primarily on the presentation of information, its accessibility, and the ability to corroborate information across multiple (online) sources. According to the participants, high quality information is found on websites that are professional looking and well organized. Participants indicated that their evaluative processes are ad hoc and contextual - a student will expend different amounts of effort based on the importance of the information sought. Wikipedia was favorably regarded by participants in terms of both its aesthetics and ease of use. A strong skepticism about the quality of results from the open-editing process seems to be the major factor limiting its use.

Finally, this study was exploratory, and as such has several limitations that should be addressed in future research. Like the majority of online credibility assessment research, we relied upon participant recollections of their behavior. There is probably some social desirability bias at work here, although the focus group participants seemed to be honest about their online informational behaviors, even when they recognized that they were suboptimal. Actual observation of student web use and informational credibility assessments would allow for more confident statements to be made. Further data collection from a broader student population would help determine how generalizable these results are.

\section{CONCLUSION}

Wikipedia presents a new model of knowledge organization and presentation that is based on shared consensus. As satirist Stephen Colbert (2006) has noted, consensus is not necessarily correlated with accuracy, and the effectiveness of collaborative processes at work on Wikipedia continue to occupy researchers (Giles, 2006; Halavais \& Lackaff, 2008). The research discussed in this paper indicates, however, that Wikipedia is already an important element of students' informational use of the Internet. Students are very familiar with Wikipedia, and many are frequent users. Wikipedia poses an interesting epistemological challenge to users as it represents a relatively novel form of information creation - open editing by semi-anonymous visitors to the site. Students may have a limited awareness of the debates surrounding the quality of information produced in this way, but are likely to make use of Wikipedia because of its broad subject coverage and high accessibility via search engines such as Google.

This paper discussed the evaluative processes that students use in their search for online information. In contrast to some previous research, we found that source authority is often not a major determinant in students' informational evaluations. This is a result of the difficulty of reliably determining source characteristics. To compensate for this lack of authority, students attempt to corroborate found information with additional sources. Additionally, heuristics based on appearance and organization of information are employed in students' search and evaluation of online information. With or without their instructors' blessings, many students are turning to informal, "user generated" information sources on the Internet. The present study indicates that educators in communication and other fields should be aware of how students are making these decisions, and integrate appropriate responses and programs to promote communication technology literacy. The current focus of Internet literacy education must take into account the changing relationship of individuals and information, and acknowledge that many traditional models of ascertaining credibility based on customary 'source and receiver' communication models are not accomplished in the online communication environment. The expanded pragmatic model introduced here hopefully represents an early step in this direction.

Future directions for this research include empirical studies of user behavior when interacting with Wikipedia, for triangulation with qualitative data as reported in this paper in order to understand better the credibility assessments among students. Wikipedia is perhaps the flagship project of the collaborative, user-driven "Web 2.0," and is challenging traditional notions of authority, credibility, and information access. As one of the mostvisited sites on the web, it plays a central role in fulfilling users' communication needs. Knowledge professionals continue to grapple with the implications of new forms of organizing and accessing knowledge. As universities discuss the merits and challenges of Wikipedia, it is useful to understand Wikipedia's place in the online communication ecosystem. 


\section{ACKNOWLEDGEMENT}

The authors wish to thank Diane Michaelsen for her assistance with the focus group phase of this research.

\section{REFERENCES}

Alexander, J.E., \& Tate, M.A. (1999). Web wisdom. Mahwah, NJ: Lawrence Erlbaum.

Association of Research Libraries. (2006). ARL Statistics, interactive edition. Charlottesville, VA: University of Virginia Library. Retrieved October 22, 2007, from http://fisher.lib.virginia.edu/arl/index.html

Bunz, E. (2004). The computer-email-web (CEW) fluency scale: Development and validation. International Journal of HumanComputer Interaction 17, 477-504.

Cheong, P. H. (2008). The Young and Techless? Investigating Internet use and problem-solving behaviors of young adults in Singapore. New Media \& Society 10(5), (in press).

Colbert, S. (July 31, 2006). Report on "Wikiality." Colbert Report. Comedy Central.

Cooke, A. (1999). Authoritative guide to evaluating information on the Internet. New York: Neal-Schuman.

Daft, R.L., Lengel, R.H., \& Trevino, L.K. (1987). Message equivocality, media selection, and manager performance: Implications for information systems. MIS Quarterly 11, 355-66.

Danielson, D. (2005). Web credibility. In C. Ghaoui (Ed.), Encyclopedia of Human-Computer Interaction (pp. 713-721). Hershey, PA: Idea Group.

Davis, P.M. (2003). Effect of the Web on undergraduate citation behavior: Guiding student scholarship in a networked age. Portal: Libraries and the Academy 3, 41-51.

Eastin, M.S. (2001). Credibility assessments of online health information: The effects of source expertise and knowledge of content. Journal of Computer-Mediated Communication, 6(4). Retrieved October 22, 2007, from http://jcmc.indiana.edu/vol6/issue4/eastin.html

Eysenbach, G., \& Köhler, C. (2002). How do consumers search for and appraise health information on the World Wide Web? Qualitative study using focus groups, usability tests, and in-depth interviews. British Medical Journal 324, 573-77.

Eysenbach, G., Powell, J., Kuss, O. \& Sa, E-. R. (2002). Empirical studies assessing the quality of health information for consumers on the World Wide Web: A systematic review. Journal of the American Medical Association 287, 2691-700.

Fallis, D. (2004). On verifying the accuracy of information: philosophical perspectives. Library Trends 52, 463-87.

Fallis, D., \& Frické, M. (2002). Indicators of accuracy of consumer health information on the Internet: A study of indicators relating to information for managing fever in children in the home. Journal of the American Medical Informatics Association 9, 73-9.

Flanagin, A.J., \& Metzger, M.J. (2007). The role of site features, user attributes, and information verification behaviors on the perceived credibility of web-based information. New Media \& Society 9, 319. 42.

Fogg, B.J. (2003). Prominence-Interpretation theory: Explaining how people assess credibility online. Proceedings of $A C M$ CHI 2003 Conference on Human Factors in Computing Systems (pp. 722723). New York: ACM Press.

Fricke, M., \& Fallis, D. (2004). Indicators of accuracy for answers to ready reference questions on the Internet. The Journal of the America Society for Information Science and Technology 55, 238-45.

Giles, J. (2006), Internet encyclopaedias go head to head. Nature 438, 9001 .

Griffiths, K.M., \& Christensen, H. (2000). Quality of Web based information on treatment of depression: Cross-sectional survey. British Medical Journal 321, 1511-5.

Halavais, A., \& Lackaff, D. (2008). An analysis of topical coverage of Wikipedia. Journal of Computer-Mediated Communication 13, 429-40.

Hargittai, E. (2002). Beyond logs and surveys: In-depth measures of people's online skills. Journal of the American Society for Information Science and Technology 53, 1239-44.

Hofer, B., \& Pintrich, P. (Eds.). (2002). Personal epistemology: The psychology of beliefs about knowledge and learning. Mahwah, NJ: Lawrence Erlbaum Associates, Inc.

Hofstetter, F.T. (2005). Internet Literacy, 4th ed. New York: McGraw-Hill.
Herring, S.D. (2001). Faculty acceptance of the World Wide Web for student research. College \& Research Libraries 62, 251-8.

Jadad, A.R., \& Gagliardi, A. (1998). Rating health information on the Internet: Navigating to knowledge or to Babel? Journal of the American Medical Association 279, 611-4.

Jones, S. (2002). The Internet goes to college: How students are living in the future with today's technology. Washington, DC: Pew Internet \& American Life Project. Retrieved October 22, 2007, from http://www.pewinternet.org/pdfs/PIP_College_Report.pdf

Krueger, R.A. (1994). Focus groups: A practical guide for applied research. Thousand Oaks, CA: Sage.

Kunst, H., Groot, D., Latthe, P.M., Latthe, M., \& Khan, K.S. (2002). Accuracy of information on apparently credible Websites: Survey of five common health topics. British Medical Journal 321, 581-2.

Lih, A. (2004). Wikipedia as participatory journalism: Reliable sources? Metrics for evaluating collaborative media as a news resource. Paper presented at the $5^{\text {th }}$ International Symposium on Online Journalism, Austin, TX. Retrieved August 17, 2007, from http://jmsc.hku.hk/faculty/alih/publications/utaustin-2004wikipedia-rc2.pdf

Liu, Z., \& Huang, X. (2005). Evaluating the credibility of scholarly information on the web: A cross cultural study. International Information \& Library Review 37, 99-106.

Metzger, M.J., Flanagin, A.J., \& Zwarun, L. (2003). College student Web use, perceptions of information credibility, and verification behavior. Computers \& Education 41, 271-90.

Pan, B., Hembrooke, H., Joachims, T., Lorigo, L., Gay, G., \& Granka, L. (2007). In Google we trust: Users' decisions on rank, position, and relevance. Journal of Computer-Mediated Communication 12(3), article 3. Retrieved October 22, 2007, from http://jcmc.indiana.edu/-vol12/issue3/pan.html

Rainie, L., \& Tancer, B. (2007). Wikipedia users. Washington, DC: Pew Internet \& American Life Project. Retrieved October 22, 2007 from http://www.pewinternet.org/pdfs/PIP Wikipedia07.pdf

Rieh, S.Y. (2002). Judgment of information quality and cognitive authority in the Web. Journal of the American Society for Information Science and Technology 53, 145-61.

Rieh, S.Y. (2005). Cognitive authority. In K.E. Fisher, S. Erdelez, \& E.F. McKechnie (Eds.), Theories of information behavior: A researcher's guide (pp. 83-87). Medford, NJ: Information Today.

Rieh, S.Y., \& Danielson, D.R. (2007). Credibility: A multidisciplinary framework. In B. Cronin (Ed.), Annual Review of Information Science and Technology, vol. 41, (pp. 307-364). Medford, NJ: Informa-tion Today.

Smith, A.G. (1997). Testing the surf: Criteria for evaluating Internet information resources. The Public-Access Computer Systems Review, 8(3). Retrieved October 22, 2007, from http://info.lib.uh.$\mathrm{edu} / \mathrm{pr} / \mathrm{v} 8 / \mathrm{n} 3 / \mathrm{smit} 8 \mathrm{n} 3 . \mathrm{html}$

Stanford, J., Tauber, E.R., Fogg, B.J., \& Marable, L. (2002). Experts vs. online consumers: A comparative credibility study of health and finance Web sites (Consumer WebWatch Research Report). Retrieved October 22, 2007, from http://www.consumerwebwatch.org/dynamic/web-credibility-reports-experts-vs-online-abstract.cfm

Suh, K.S. (1999). Impact of communication medium on task performance and satisfaction: An examination of media-richness theory. Information \& Management 35, 295-312.

Tenopir, C. (2003). Use and users of electronic library resources: An overview and analysis of recent research studies. Council on Library and Information Resources. Retrieved October 22, 2007, from http://www.clir.org/pubs/abstract/pub120abst.html

Thompson, C. (2003). Information illiterate or lazy: How college students use the web for research. Portal: Libraries and the Academy 3 259-68.

Trevino, L.K., Lengel, R.K. \& Daft, R.L. (1987). Media symbolism, media richness and media choice in organizations. Communication Research 14, 553-74.

Vishwanath, A. (2007). Information search efficacy: A new measure and its initial tests. Communication Research Reports 24, 195-203.

Whitmire, E. (2004). The relationship between undergraduates' epistemological beliefs, reflective judgment, and their information-seeking behavior. Information Processing \& Management 40, 97-111.

Wilkinson, G.L., Bennett, L.T., \& Oliver, K.M. (1997). Evaluation criteria and indicators of quality for Internet resources. Educational Technology 37, 52-9. 
Wilson, P. (1983). Second-hand knowledge: An inquiry into cognitive authority. Westport, CT: Greenwood Press.

Wikipedia:About. (2007). In Wikipedia, The Free Encyclopedia. Retrieved October 22, 2007, from http://en.wikipedia.org/w/index.php?title=Wikipedia:About\&oldid $=165815721$
Wood, P., \& Kardash, C.M. (2002). Critical elements in the design and analysis of critical thinking studies. In B. Hofer P, Pintrich (Eds.), Personal epistemology: The psychology of beliefs about knowledge and learning (pp. 231-260). Mahwah, NJ: Lawrence Erlbaum.

(C) Lackaff and Cheong; Licensee Bentham Open.

This is an open access article licensed under the terms of the Creative Commons Attribution Non-Commercial License (http://creativecommons.org/licenses/by-nc/3.0/) which permits unrestricted, non-commercial use, distribution and reproduction in any medium, provided the work is properly cited. 